\title{
Prospective surveillance of healthcare- associated infections and patterns of antimicrobial resistance of pathogens in an Italian intensive care unit
}

\author{
Aida Bianco, Maria Simona Capano, Valentina Mascaro, Claudia Pileggi and Maria Pavia*
}

\begin{abstract}
Background: The study aimed to evaluate the distribution of healthcare-associated infections (HAls), the incidence rates and device utilization ratio (DUR) of device-associated infections (DAls), as well as the distribution and patterns of antimicrobial resistance of the responsible pathogens.

Methods: Eligible patients who were admitted to an adult Intensive Care Unit (ICU) from May 1, 2013 to December 31, 2016 were included in the surveillance. Demographics, intrinsic and extrinsic risk factors, information regarding infection and isolated pathogens with antibiogram results were collected.

Results: One thousand two hundred eighty-three patients were included in the surveillance. One hundred forty-seven HAls were detected with a cumulative incidence of 9.2 per 100 patients 4-year period and an incidence rate of 17.4 per 1000 patient days. Fifty-six out of 1283 patients were affected by at least one episode of ICU-acquired pneumonia, and 72.7\% of these were associated with intubation. ICU-acquired bloodstream infections (BSIs) occurred in $4.4 \%$ of patients and $89.5 \%$ were catheter-related. ICU-acquired urinary tract infections (UTIs) occurred in 1\% of patients, with $84.6 \%$ of the episodes being associated with the use of an urinary catheter. The pattern of antimicrobial-resistance in the isolates showed, among the Gram-positive bacteria, that $66.6 \%$ and $16.6 \%$ of Staphylococcus epidermidis were oxacillin and teicoplanin resistant, respectively. Among the Gram-negative bacteria, carbapenem resistance was found in 91. $6 \%$ of Acinetobacter baumannii and $28.5 \%$ of Klebsiella pneumoniae isolates.
\end{abstract}

Conclusions: The majority of HAls in the ICU studied were associated with the use of invasive devices. Since a significant proportion of these HAls are considered preventable, reinforcement of the evidence-based preventive procedures are needed.

Keywords: Healthcare-associated infection, Intensive care unit, Italy, Surveillance

\section{Background}

Healthcare-associated infections (HAIs) represent a major threat to patient safety, leading to significant mortality and financial losses for health systems worldwide. In highincome countries, for every 100 hospitalized patients, 7 develop at least one HAI and the frequency of HAIs acquired by patients in intensive care units (ICUs) is at least 3 fold higher (approximately 30\%) [1].

\footnotetext{
* Correspondence: pavia@unicz.it

Department of Health Sciences, University of Catanzaro "Magna Græcia", Via T. Campanella, 115, 88100 Catanzaro, Italy
}

In Europe it is estimated that $4,131,000$ patients are affected by HAI and approximately about 4,544,100 episodes occur each year [2]. HAIs cause 16 million extra days of hospital stay and 37,000 attributable deaths. The burden of HAIs in patients admitted to ICUs vary from 9.7-31.8\% in Europe [3].

In Italy, a national network for the prospective surveillance of HAIs in all wards is not in place. Continuous multicenter infection surveillance systems have been adopted in ICUs, and reported cumulative incidence range from 9.1 [4] to 15.5 per 100 patients [5]. 
Table 1 Incidence of device-associated infections (DAls) by site, 2013-2016

\begin{tabular}{|c|c|c|c|c|c|c|c|c|c|c|c|c|}
\hline \multirow[t]{2}{*}{ Year } & \multicolumn{4}{|c|}{ VAP } & \multicolumn{4}{|c|}{ CLABSI } & \multicolumn{4}{|c|}{ CAUTI } \\
\hline & $\bar{n}$ & MVdays & Rate $^{a}$ & $\mathrm{DUR} \mathrm{R}^{\mathrm{b}}$ & $n$ & CLdays & Rate $^{a}$ & $\mathrm{DUR}^{\mathrm{b}}$ & $n$ & UCdays & Rate $^{a}$ & $D \mathrm{R}^{\mathrm{b}}$ \\
\hline 2013 & 12 & 502 & 23.9 & 0.32 & 14 & 1241 & 11.2 & 0.81 & 0 & 1224 & $0^{c}$ & 0.80 \\
\hline 2014 & 24 & 897 & 26.7 & 0.34 & 15 & 2255 & 6.6 & 0.86 & 2 & 2258 & 0.9 & 0.86 \\
\hline 2015 & 10 & 915 & 10.9 & 0.40 & 10 & 1535 & 6.5 & 0.67 & 6 & 1560 & 3.8 & 0.68 \\
\hline 2016 & 10 & 826 & 12.1 & 0.40 & 12 & 1528 & 7.8 & 0.75 & 3 & 1528 & 1.9 & 0.75 \\
\hline TOTAL & 56 & 3140 & 73.6 & 1.46 & 51 & 6559 & 32.1 & 3.09 & 11 & 6570 & 6.6 & 3.09 \\
\hline
\end{tabular}

NOTE. VAP ventilator-associated pneumonia, CLABSI central line-associated bloodstream infection, CAUTI catheter-associated urinary tract infection, MV mechanical ventilator , DUR device utilization ratio, $C L$ central line, UC urinary catheter

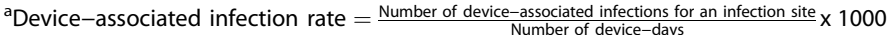

${ }^{\mathrm{b}}$ Device utilization ratio $($ DUR $)=\frac{\text { Number of device-days }}{\text { Number of patient-days }}$

'The rate was not calculated since the number of CAUTI in 2013 was 0

In the literature, variable proportions of HAIs, considered to be preventable by intensive hygiene and control programs, have been reported [6, 7]. Among the infection prevention initiatives, surveillance of HAIs is the cornerstone to decrease infection rates in hospitalized patients [8], and it is considered to be the best way to assure patient safety [9]. Continuous monitoring of HAI rates can be used to assess effectiveness of interventions and provides information which may be used for benchmarking comparison [10]. Routine surveillance of HAIs should become an integral part of infection prevention and quality assurance in hospitals [11].

This study reports the results of a 4-year period prospective surveillance in an ICU in an Italian teaching hospital aimed at evaluating: 1) the cumulative incidence and incidence rate of HAIs; 2) the incidence rates of device-associated infections (DAIs); 3 ) the device utilization ratio (DUR); 4) the distribution of the responsible pathogens; and 5) the patterns of their antimicrobial resistance.

\section{Methods}

An HAIs surveillance system based on that of the Centers for Disease Control and Prevention's (CDC) National Healthcare Safety Network (NHSN) [12] was established in 2013 by the Hospital Prevention \& Control Group for the prospective surveillance of events and their corresponding denominator data by trained Infection Preventionists in an adult ICU.

\section{Setting and patients}

The ICU is an 8-bed unit that is part of a universityaffiliated teaching hospital, with two single rooms for isolation. The ICU type was classified according to the NHSN criteria as a medical/surgical unit of a major teaching hospital. It has approximately 382 admissions per year.

All eligible patients admitted from May 1, 2013 to December 31, 2016 have been included in the surveillance.
Patients who were transferred to the ICU from an outside hospital are also included. The exclusion criteria were patients with a community acquired infection, ICU stay for less than $48 \mathrm{~h}$ and death within $48 \mathrm{~h}$ of ICU admission. The follow-up of each patient was continued until discharge, referral, or death.

\section{Data collection}

Surveillance data on all ICU-acquired HAIs, both in patients with or without a device, and their causative pathogens were collected prospectively on a specifically designed form (Additional file 1) by the investigators using medical records comprising charts, daily flow sheets, laboratory (eg, complete blood count, serology, microbiology, biochemistry) and radiographic results. The collected data included demographics; intrinsic and extrinsic risk factors for infection; date of infection onset; clinical signs; administered antibiotics; isolated pathogens with antibiogram results; and outcome on discharge from the ICU. The risk factors were evaluated from the time of admission until the onset of HAI. For patients who did not develop HAI, the risk factors were evaluated for their entire ICU stay.

The definitions of HAIs, and DURs are based on those established by the CDC, which are used by the NHSN system [13]. Particular attention is paid to data on DAIs [ventilator-associated pneumonias (VAPs), central line-associated bloodstream infections (CLABSIs), and catheter-associated urinary tract infections (CAUTIs)], and denominator data (patient days and specific device days). An infection is defined as device-associated (i.e., mechanical ventilator (MV), urinary catheter (UC), or central line-associated (CL)) if the corresponding device was in place on the date of infection and within two calendar days prior. Surgical site infections were not monitored because we performed a ward-based surveillance, rather than a procedure-based surveillance.

Global prevalence of the pathogens causing DAIs and antimicrobial resistance rates are also calculated. 
Multidrug-resistance (MDR) is defined in accordance with current published interim standard definitions, which are used in the most recent NHSN antimicrobial resistance report [14].

\section{Statistical analysis}

Rates and ratios are calculated according to standard methods [12]. Briefly, DUR are calculated as the total number of MV, CL, or UC days, divided by the total number of patient days. The infection frequency is calculated as the number of infections per 100 ICU eligible patients (cumulative incidence) and the number of infections per 1000 patient-days (incidence rate). Rates for DAIs are reported as the number of infections per 1000 device days.

The first part of the analysis examines the entire cohort of patients. Data are summarized using the mean and standard deviation (SD) for continuous variables and frequency and percentage for discrete and nominal variables. Univariate analysis was tentatively used to compare variables for the outcome groups of interest (HAIs versus no HAIs), and all tests of significance were two tailed. The $\mathrm{T}$ test was used for comparing continuous variables, while the $x^{2}$-statistic or Fisher-exact test was used for discrete and nominal variables. All statistical analyses were performed using the Stata software program, version 14 (Stata).

\section{Results}

During the 4 year study period, 1283 patients were included in the surveillance. The population mean age was $66( \pm 12)$ years and $841(66 \%)$ were males. Overall, 147 ICU-acquired HAIs were detected with a cumulative incidence of 9.2 per 100 patients 4-year period and an incidence rate of 17.4 per 1000 patient days. A total of 118 DAIs were found, of which $38.1 \%$ were VAPs, $34.7 \%$ CLABSIs and 7.5\% CAUTIs.

In the population, 56 out of 1283 patients (6\%) were affected by at least one episode of ICUacquired pneumonia, and $72.7 \%$ of these were VAPs. The incidence rate of ICU-acquired pneumonia was 9 episodes per 1000 patient-days and VAP incidence rate was 17.8 per $1000 \mathrm{MV}$ days ( $>90^{\text {th }}$ percentile).

On average, ICU-acquired BSIs occurred in $4.4 \%$ of patients staying in an ICU for more than 2 days. The incidence rate was 6.8 BSI episodes per 1000 patient-days. $89.5 \%$ of cases were CLABSIs with an incidence rate of 7.7 per $1000 \mathrm{CL}$ days (> $90^{\text {th }}$ percentile).

On average, ICU-acquired urinary tract infections (UTIs) occurred in $1 \%$ of patients staying in an ICU for more than 2 days, with $84.6 \%$ of UTI episodes being associated with the use of a UC The incidence rate per ICU was 1.5 UTI episodes per 1000 patient-days and a mean device-adjusted rate of 1.6 CAUTI episodes per $1000 \mathrm{UC}$-days $\left(25^{\text {th }}-50^{\text {th }}\right.$ percentile).

The trend during the surveillance period showed that the rate of VAP considerably decreased from 23.9 in 2013 to 12.1 in 2016 per 1000 MV days; CLABSI reduced from 11.2 in 2013 to 7.8 in 2016 per 1000 CL days. The incidence rate of CAUTI had been constantly contained during the surveillance period, ranging from 0 in 2013 to 3.8 in 2015, while in 2016 it was found to be 1.9 per 1000 UC days (Table 1).

Among Gram-negative bacteria, the most common isolated pathogens were Klebsiella pneumoniae (17.8\%), Acinetobacter baumannii (10.2\%), Escherichia coli (8. 5\%), Pseudomonas aeruginosa (5\%); among Grampositive bacteria Staphylococcus epidermidis (10\%) was the most common. All yeasts found were classified as Candida species. Throughout the surveillance period, Klebsiella pneumoniae was the most frequent pathogen associated with VAPs $(n=12)$ followed by Acinetobacter baumannii $(n=6)$, Escherichia coli $(n=6)$ and Pseudomonas aeruginosa $(n=6)$. Thirteen VAP episodes were non-microbiologically confirmed. The most frequently isolated microorganisms in ICU-acquired CLABSI episodes were coagulase-negative staphylococci $(n=21)$ and of these 11 were Staphylococcus epidermidis; among Gram-negative bacteria Klebsiella pneumoniae $(n=7)$ and Acinetobacter baumannii $(n=5)$ were the most frequent isolates. Candida species (45.4\%) and Klebsiella pneumoniae (18.1\%) were the most frequently isolated microorganisms in CAUTI episodes.

The antimicrobial-resistance in the isolates associated with ICU-acquired DAIs showed, among the Gram-positive bacteria, that $66.6 \%$ and $16.6 \%$ of Staphylococcus epidermidis isolates were $\beta$-lactam (oxacillin) - and glycopeptide (teicoplanin) - resistant, respectively. Among the Gram-negative bacteria thirdgeneration cephalosporins (cefotaxime or ceftazidime) resistance was found in $52.3 \%$ of Klebsiella pneumoniae and 30\% of Escherichia coli isolates; and carbapenem (imipenem, meropenem, ertapenem) resistance in $91.6 \%$ of Acinetobacter baumannii and 28.5\% of Klebsiella pneumoniae isolates. MDR phenotypes were reported in all Pseudomonas aeruginosa, in Acinetobacter baumannii (91.6\%), Escherichia coli (40\%) and Klebsiella pneumoniae (52.3\%) isolates. Resistance to colistin, an antibiotic from the polymyxin group, was observed in $4 \%$ of the Klebsiella pneumoniae isolates.

Results of univariate analysis showed that no statistically significant difference between infection and the independent covariates was found (data not shown).

\section{Discussion}

The cumulative incidence of HAIs in ICU wards varies widely among countries (5\%-38.9\%) [15], and the 
detected rate in the present surveillance (9.2\%) was in the range of values specified in other studies. Data reported by The European Surveillance System showed that, in 2014, $8 \%$ of the patients staying in the ICU for more than 2 days presented at least one HAI [16]. The HAI incidence rate of 17.4 per 1000 patient days was slightly higher than that noticed in the study from the USA where the rate of HAI in an adult ICU was shown to be 16.2 per 1000 patient days[17]. The majority of HAIs in ICUs are associated with the use of invasive devices. Therefore, our surveillance system paid particular attention to DAIs, since a significant proportion of these HAIs are considered preventable. The findings showed that the most common DAI was VAP (47.5\%), consistent with the reported literature. Globally, the VAP rate we observed (17.8/1000 MV days) was higher than the surveillance data from Germany (5.4/1000 MV days) [18] and from the United States where the VAP incidence rate was 2.1 per 1000 device days in medical/surgical major teaching ICUs [19]. A more pertinent benchmarking information could be obtained on a national scale. The cumulative incidence of the ICU-acquired HAIs (9. $2 \%$ ) is very similar to that reported in a continuous multicenter infection surveillance program (9.1\%) involving 125 Italian ICUs promoted by the Italian Group for the Evaluation of Interventions in Intensive Care Medicine [4]. Similarly, VAP was the most frequently diagnosed, but the incidence rate was lower than that reported in the present surveillance program (8.9/ 1000 vs $17.8 / 1000$ MV days) [4]. However, the Italian Nosocomial Infections Surveillance in ICUs network, SPIN-UTI, reported surveillance data from a 6-year period (2006-2011), with a third survey showing a more similar VAP incidence rate (17.3 per $1000 \mathrm{MV}$ days) [20], while the VAP incidence rate was higher in a surveillance program organized in an Italian singlecentre 12-bed ICU (23.14/1000 MV days) [21].

The CLABSI incidence rate (7.7 per 1000 CL days) we observed was much lower than that reported from limited-resource countries [22, 23], but higher than 1 . 1 per $1000 \mathrm{CL}$ days reported in the medical/surgical major teaching ICUs in the healthcare facilities adhering to NHSN surveillance [19]. In the SPIN-UTI, in the 2010-2011 survey, and in the GiViTi projects the CLABSI incidence rate was 1.8 and 1.9 per 1000 CVC days, respectively $[20,4]$. The higher rate in the present surveillance could be explained by a high CL utilization ratio, exceeding the 90th percentile of the NHSN distribution for medical/surgical major teaching ICUs. Intravascular devices remain an essential component of ICU care, but many studies recognize CL duration as a risk factor for CLABSI [24, 25].

The reasons for lower CAUTI rates observed in the present study compared with other studies may be related to the effectiveness of the interventions implemented in our setting. They included educational strategies, UC avoidance, policies for UC insertion, daily necessity review and limiting catheter days that have been proven to decrease CAUTI events [26].

In the present study Gram-negative bacteria were the most common causal pathogens, in agreement with several surveillance studies in the United States [27], Europe [28], Saudi Arabia [29] and Brazil [30]. Among these Gram-negative bacteria, Klebsiella pneumoniae (17.8\%) and Acinetobacter baumannii (10.2\%) were the most frequently reported. This finding is of particular concern, since these organisms are often involved in outbreaks that require the activation of an organizational response until the outbreak is under control [31].

In the present study, the high level of resistance to multiple antibiotics is of great concern, especially since resistance to colistin was also reported. This condition represents an indication of seriously limited options for the treatment of patients infected with those microorganisms.

A variability in DAI rates across the surveillance period can be observed. Part of this variability can be attributed to the small number of episodes, and characteristics of the patient population, such as clinical severity and infection control practices that had been reinforced during surveillance. Over the 4 year study several infection control practices, such as the active surveillance cultures to detect asymptomatic colonization and preemptive contact isolation of patients were implemented.

The strengths of the study lie in the prospective nature, and application of NHSN methodology. It is well known that indicators of HAIs provided by surveillance activities require comparison with adequate reference data to stimulate further infection control actions and to enhance quality of care [32]. The NHSN methodology has proven to be adaptable in our context and useful as benchmark.

This study had a couple of limitations. An HAI incidence study should preferably be performed on large cohorts, taken from a national ICU sample. The consequence of a small population size is the low probability of detecting an important effect, since the analysis is underpowered. For this reason, we did not show the results of the univariate analysis. The present surveillance was conducted in one adult ICU in Southern Italy, and the results cannot be generalized to all public Italian hospital settings. It is reasonable to suppose that an analogous context may be referred to the Southern part of our country.

\section{Conclusion}

Given the limitations cited above, the authors believe that to have more insight into HAI indicators as measured by 
a surveillance system, it is crucial to estimate the burden of HAIs and to compare the performance to that of other contexts, as well as to evaluate new preventive procedures.

\section{Additional file}

Additional file 1: Data Collection Form. (DOC $330 \mathrm{~kb}$ )

Acknowledgements

Not applicable

\section{Funding}

No external funding for this manuscript.

\section{Availability of data and materials}

The datasets used and/or analysed during the current study are available from the corresponding author on reasonable request.

\section{Authors' contributions}

$A B$ made substantial contributions to the conception and design of the study, to analysis and interpretation of the data and wrote the paper. MSC, VM and CP collected the data, contributed to analysis of the data and drafting of the paper. MP made substantial contributions in the design of the study, was responsible for analysis of the data and revising the paper critically for important intellectual content. All authors approved the final paper as submitted, and agree to be accountable for all aspects of the work in ensuring that questions related to the accuracy or integrity of any part of the work are appropriately investigated and resolved. $A B$ and $M P$ are guarantors for the study.

Ethics approval and consent to participate

Not applicable

\section{Consent for publication}

Not applicable

\section{Competing interests}

The authors declare that they have no competing interests.

\section{Publisher's Note}

Springer Nature remains neutral with regard to jurisdictional claims in published maps and institutional affiliations.

\section{Received: 20 December 2017 Accepted: 21 March 2018}

Published online: 03 April 2018

\section{References}

1. World Health Organization. Healthcare-associated infections: fact sheet: 2014. Available at http://www.who.int/gpsc/country_work/gpsc_ccisc_fact_ sheet_en.pdf. Accessed 4 May 2017.

2. World Health Organization. The Burden of Health Care-Associated Infection Worldwide. A Summary; 2010. Available at http://www.who.int/gpsc/ country_work/summary_20100430 en.pdf. Accessed 10 Feb 2017.

3. Vincent JL, Bihari DJ, Suter PM, Bruining HA, White J, Nicolas-Chanoin $\mathrm{MH}$, et al. The prevalence of nosocomial infection in intensive care units in Europe. Results of the European prevalence of infection in intensive care (EPIC) study. EPIC international advisory committee. JAMA. 1995:274:639-44.

4. Malacarne P, Boccalatte D, Acquarolo A, Agostini F, Anghileri A, Giardino M, et al. Epidemiology of nosocomial infection in 125 Italian intensive care units. Minerva Anestesiol. 2010;76:13-23.

5. Masia MD, Barchitta M, Liperi G, Cantu AP, Alliata E. Validation of intensive care unit-acquired infection surveillance in the Italian SPIN-UTI network. J Hosp Infect. 2010;76:139-42.

6. Brown J, Doloresco FIII, Mylotte JM. "Never events": not every hospitalacquired infection is preventable. Clin Infect Dis. 2009;49:743-6.

7. Harbarth S, Sax H, Gastmeier P. The preventable proportion of nosocomial infections: an overview of published reports. J Hosp Infect. 2003;54:258-66.
8. O'Neill E, Humphreys $\mathrm{H}$. Use of surveillance data for prevention of healthcare-associated infection: risk adjustment and reporting dilemmas. Curr Opin Infect Dis. 2009;22:359-63.

9. Van Bunnik BA, Ciccolini M, Gibbons CL, Edwards G, Fitzgerald R, McAdam $P R$, et al. Efficient national surveillance for health-care-associated infections. BMC Public Health. 2015;15:832.

10. Mitchell BG, Russo PL. Preventing healthcare-associated infections: the role of surveillance. Nurs Stand. 2015:2952-8.

11. Gastmeier P, Geffers C, Brandt C, Zuschneid I, Sohr D, Schwab F, et al. Effectiveness of a nationwide nosocomial infection surveillance system for reducing nosocomial infections. J Hosp Infect. 2006;64:16-22.

12. Dudeck MA, Horan TC, Peterson KD, Allen-Bridson K, Morrell G, Anttila A, et al. National Healthcare Safety Network report, data summary for 2011, device-associated module. Am J Infect Control. 2013;41:286-300.

13. Horan TC, Andrus M, Dudeck MA. CDC/NHSN surveillance definition of health care-associated infection and criteria for specific types of infections in the acute care setting. Am J Infect Control. 2008:36:309-32.

14. Magiorakos AP, Srinivasan A, Carey RB, Carmeli Y, Falagas ME, Giske CG, et al. Multidrug-resistant, extensively drug-resistant and pandrug-resistant bacteria: an international expert proposal for interim standard definitions for acquired resistance. Clin Microbiol Infect. 2012;18:268-81.

15. World Health Organization. Education sessions for trainers, observers and health-care workers. 2009. Available at https://www.ntuh.gov.tw/ifc/hhc/ HandHygiene/Education\%20Sessions\%20for\%20Trainers\%20and\%20 Observers\%20and\%20Health-care\%20Workers.pdf Accessed 02 Sept 2017.

16. Center for Disease Control and Prevention. Healthcare-associated infections acquired in intensive care units. 2016. Available at https://ecdc.europa.eu/ en/publications-data/healthcare-associated-infections-acquired-intensivecare-units-annual Accessed 28 Sept 2017

17. Richards MJ, Edwards JR, Culver DH, Gaynes RP. Nosocomial infections in combined medical-surgical intensive care units in the United States. Infect Control Hosp Epidemiol. 2000;21:510-5.

18. Kohlenberg A, Schwab F, Behnke M, Geffers C, Gastmeier P. Pneumonia associated with invasive and noninvasive ventilation: an analysis of the German nosocomial infection surveillance system database. Intensive Care Med. 2010;36:971-8.

19. Dudeck MA, Edwards JR, Allen-Bridson K, Gross C, Malpiedi PJ, Peterson KD, et al. National Healthcare Safety Network report, data summary for 2013, device-associated module. Am J Infect Control. 2015;43:206-21.

20. Agodi A, Auxilia F, Barchitta M, Brusaferro S, D'Alessandro D, Grillo OC, et al. GISIO-SITI. Trends, risk factors and outcomes of healthcare-associated infections within the Italian network SPIN-UTI. J Hosp Infect. 2013;84:52-8.

21. Boncagni F, Francolini R, Nataloni S, Skrami E, Gesuita R, Donati A, et al. Epidemiology and clinical outcome of healthcare-associated infections: a 4- year experience of an Italian ICU. Minerva Anestesiol. 2015;81:765-75

22. Talaat M, El-Shokry M, El-Kholy J, Ismail G, Kotb S, Hafez S, et al. National surveillance of health care-associated infections in Egypt: developing a sustainable program in a resource-limited country. Am J Infect Control. 2016:44:1296-301.

23. Dereli N, Ozayar E, Degerli S, Sahin S, Koç F. Three-year evaluation of nosocomial infection rates of the ICU. Braz J Anesthesiol. 2013;63:73-8.

24. Mer M, Duse AG, Galpin JS, Richards GA. Central venous catheterization: a prospective, randomized, double-blind study. Clin Appl Thromb Hemost. 2009;15:19-26

25. Sheridan RL, Weber JM. Mechanical and infectious complications of central venous cannulation in children: lessons learned from a 10-year experience placing more than 1000 catheters. J Burn Care Res. 2006;27:713-8.

26. Galiczewski JM. Interventions for the prevention of catheter associated urinary tract infections in intensive care units: an integrative review. Intensive Crit Care Nurs. 2016;32:1-11.

27. Weiner LM, Webb AK, Limbago B, Dudeck MA, Patel J, Kallen AJ, et al. Antimicrobial-resistant pathogens associated with healthcare-associated infections: summary of data reported to the National Healthcare Safety Network at the Centers for Disease Control and Prevention, 2009-2010. Infect Control Hosp Epidemiol. 2013:34:1-14.

28. Vincent JL. Nosocomial infections in adult intensive care units. Lancet. 2003; 361:2068-77.

29. Khan MA. Bacterial spectrum and susceptibility patterns of pathogens in ICU and IMCU of a secondary care hospital in Kingdom of Saudi Arabia. Int J Pathol. 2012;10:64-70 
30. Rubio FG, Oliveira VD, Rangel RM, Nogueira MC, Almeida MT. Trends in bacterial resistance in a tertiary university hospital over one decade. Braz Infect Dis. 2013;17:480-2.

31. Bianco A, Quirino A, Giordano M, Marano V, Rizzo C, Liberto MC, et al. Control of carbapenem-resistant Acinetobacter baumannii outbreak in an intensive care unit of a teaching hospital in southern Italy. BMC Infect Dis. 2016;16:747.

32. Center for Disease Control and Prevention. Surveillance of healthcareassociated infections and prevention indicators in European intensive care units. 2017. Availdable at https://ecdc.europa.eu/sites/portal/files/ documents/HAI-Net-ICU-protocol-v2.2_0.pdf. Accessed 10 July 2017.

Submit your next manuscript to BioMed Central and we will help you at every step:

- We accept pre-submission inquiries

- Our selector tool helps you to find the most relevant journal

- We provide round the clock customer support

- Convenient online submission

- Thorough peer review

- Inclusion in PubMed and all major indexing services

- Maximum visibility for your research

Submit your manuscript at www.biomedcentral.com/submit
Biomed Central 